\title{
EFICACIA Y TOLERABILIDAD DEL CARBÓN ACTIVADO MAS PLATA EN EL TRATAMIENTO LOCALDE HERIDAS INFECTADAS
}

\author{
EFFICACY AND TOLERABILITY OF ACTIVATED COAL PLUS SILVER IN THE LOCAL TREATMENT OF \\ INFECTED WOUNDS
}

\author{
EFICÁCIA E TOLERABILIDADE DO CARBONO ATIVADO MAIS PRATA NO TRATAMENTO LOCAL DE \\ FERIDAS INFECTADAS
}

\author{
MARTHA HERAS VELOZ', CONSUELO POZO CAMACHO', RODOLFO GALÁN SÁNCHEZ1,2, ENRIQUE URAGA PAZMIÑO² \\ 1 Universidad Católica de Santiago de Guayaquil, Guayaquil, Ecuador \\ 2 Hospital Luis Vernaza, Guayaquil, Ecuador
}

Actualmente la terapia basada en el principio de proveer humedad en el ambiente de una herida se conoce como cuidado avanzado de heridas. Existe una gran cantidad de apósitos activos que se utilizan en hospitales y centros privados por ejemplo, los que contienen carbón activado más plata, hidrocoloides, alginatos, hidropolímeros, todos ellos promueven humedad y debridamiento autolítico. El propósito de este estudio fue valorar la eficacia y tolerabilidad del carbón activado más plata en heridas infectadas. Dieciséis pacientes (10 mujeres y 6 hombres) con úlceras de diversa etiología internados en el servicio médico de Dermatología del hospital Luis Vernaza, Guayaquil formaron parte de este estudio por un tiempo de 4 años. Se registró el tamaño de las heridas y se realizaron cultivos bacterianos de las úlceras, el registro fotográfico; se realizó al inicio y en cada recambio de apósito. De los dieciséis pacientes solo uno abandonó el estudio, una paciente epitelizó el 100\%, en los restantes se observó aumento del tejido de granulación y disminución del exudado. El objetivo del estudio fué preparar las ulceras para tratamiento quirúrgico, salvo el caso que epitelizó el 100\%, el cual deja una ventana abierta en pacientes seleccionados en donde se puede llegar al cierre definitivo. El tejido periulceral permaneció indemne durante todo el tratamiento. Este estudio propone que el tratamiento local de heridas infectadas con carbón activado más plata, es eficaz ya que permite un apropiado manejo de la infección bacteriana y un correcto ambiente húmedo.

PALABRAS CLAVE: heridas, plata, úlceras, dermatología.

Abstract

To promote the moisture of a wound's environment is known as advance wound care in the recent years. There are many active dressings which are used in Hospitals and in private clinics; one example is activated coal plus silver dressings, hydrocolloids, alginates and hydro-polymers. All of them provide moisture and autolytic debridement. The purpose of this study is to measure the efficacy and tolerability of activated coal plus silver in infected wounds. 16 patients (10 women and 6 men) with diverse etiology ulcers in the Dermatology department of Luis Vernaza Hospital in Guayaquil were included in this study for a 4 year period. The size of the wound and bacterial culture were registered. Photographs were taken before and at each dressing change. Of the 16 participants just one abandoned the study, 1 of them epithelized $100 \%$ of the wound and the rest of the patients had a decrease in the exudate and increase of granulation tissue. The main objective of this study was to prepare the wounds for surgical treatment except for the case in which the epithelization was $100 \%$ and this event can lead us to believe that some patients can achieve complete closure of their wound. The near-ulcer tissue was intact during the treatment. This study proposes that the local treatment of infected wounds with activated coal plus silver is effective and achieves a good profile for the management of bacterial infection and a good moist environment

KEYWORDS: wound, silver, ulcers, dermatology.

Resumo

Atualmente, a terapia baseada no princípio de fornecer umidade no ambiente de uma ferida é conhecida como tratamento avançado de feridas. Existe um grande número de curativos ativos usados em hospitais e centros privados, por exemplo, aqueles que contêm carvão ativado mais prata, hidrocolóides, alginatos, hidroponímeros, todos eles promovem umidade e desbridamento autolítico. 0 objetivo deste estudo foi avaliar a eficácia e tolerabilidade do carvão ativado mais prata em feridas infectadas. Dezesseis pacientes (10 mulheres e 6 homens) com úlceras de etiologia diversa admitidos no Serviço Médico de Dermatologia do Hospital Luis Vernaza em Guayaquil fizeram parte deste estudo por um período de 4 anos. 0 tamanho das feridas foi registrado e as culturas bacterianas das úlceras foram realizadas, o registro fotográfico foi realizado no início e em cada troca de curativo. Dos dezesseis pacientes, apenas um deixou o estudo, um paciente epitelizou 100\%; nos demais, houve um aumento no tecido de granulação e uma diminuição no exsudato. 0 objetivo do estudo foi preparar as úlceras para tratamento cirúrgico, exceto no caso 100\% epitelizado, o que deixa uma janela aberta em pacientes selecionados, onde o fechamento definitivo pode ser alcançado. 0 tecido periulceral permaneceu ileso durante todo o tratamento. Este estudo propõe que o tratamento local de feridas infectadas com carvão ativado e prata seja eficaz, pois permite um gerenciamento adequado da infecção bacteriana e um correto ambiente úmido

PALAVRAS-CHAVE: feridas, prata, úlceras, dermatologia. 
INTRODUCCIÓN

Los últimos avances en el tratamiento de las heridas demuestran que la cicatrización en ambiente húmedo es más rápida que aquella que se realiza en ambiente seco, desde los estudios de Winter y Scales en $1.963^{1}$ y los que le siguen Vranckx ${ }^{2}$ plantean que el ambiente húmedo otorga un medio muy natural, lo que facilitará una reparación tisular sin alteraciones.

El uso del carbón activado en combinación con otras sustancias (ingredientes activos) produce una acción combinada de sustancias que favorecen sinérgicamente la acción antibacteriana de la plata, ${ }^{3}$ ya que tiene la particularidad de fijar los microorganismos y de evitar la multiplicación de ellos. La plata, al actuar a diversos sitios de los microroganismos patógenos elude la resistencia bacteriana. ${ }^{4-6}$ El uso de apósitos que contienen plata para el manejo de heridas infectadas es cada vez más frecuente, hay reportes de que la plata posee propiedades antiinflamatorias ya que disminuye la actividad de las metaloproteinasas, las mismas que están elevadas en las heridas crónicas..$^{7-12}$ Es$^{-}$ tas numerosas propiedades de la plata permiten que sea un antimicrobiano tópico ideal y seguro para heridas con infección.

Hay que destacar que la finalidad principal de utilizar apósitos que contengan plata es tratar la infección local y prevenir la diseminación sistémica y no obtener la epitelización completa, ${ }^{13}$ cabe recalcar que también existe una suposición errónea de que los apósitos con plata producen efectos tóxicos sistémicos como la argiriasis. En ocasiones, los apósitos de plata producen una coloración o tinción local en la piel que es inocua y habitualmente reversible. ${ }^{14}$

En la literatura revisada también se encontró otras alternativas como la aplicación de presión negativa (PN) para el manejo de heridas de mayor tamaño, en este estudio lo comparan con un gel de plasma rico en proteínas el cual resulta más costoso. ${ }^{15}$

\section{MATERIALES Y MÉTODOS}

El presente estudio fué desarrollado en Guayaquil Ecuador, en pacientes que acudieron al servicio de dermatología del hospital Luis Vernaza en el periodo comprendido desde enero de 2004 hasta julio de 2008; el motivo de ingreso de los pacientes fué ulceras de diversa etiología. Se comunicó al comité de ética del hospital el propósito de realizar este estudio, se obtuvo la aprobación, a todos los pacientes se les informó acerca del tipo de apósito que se utilizaría en el manejo local de sus heridas.

Todos los pacientes firmaron un consentimiento firmado antes de iniciar el tratamiento local. La historia clínica incluyó datos como; edad, procedencia, lugar de origen, ocupación, antecedentes patológicos, medicamentos. La historia clínica dermatológica incluyó topografía, tamaño, tiempo de evolución, etiología, datos semiológicos de las úlceras como dolor, piel perilesional, exudado, bordes, fondo, fibrina, tejido de granulación. Se investigó la presencia de enfermedades sistémicas.

Dentro de los exámenes de laboratorio se solicitó; biometría hemática, glicemia, perfil renal, perfil hepático, físico químico y sedimento de orina, biopsia de piel con recuento de unidades formadoras de colonia más estudio dermatopatológico.

Además se solicitó eco doppler arterial y venosos de miembros inferiores. El tamaño de las heridas se registró al inicio del tratamiento.

El tamaño de las úlceras fué medida con cinta milimetrada de papel, tomando como referencia el eje más largo y el eje más ancho de la úlcera.

Eldolor se consideró si era: leve, moderado, severo o sindolor. El cambio delos apósitos inicialmentefué diario hasta la séptima curación; luego el recambio fué en un promedio de cada 5 días aproximadamente. Figura 1.

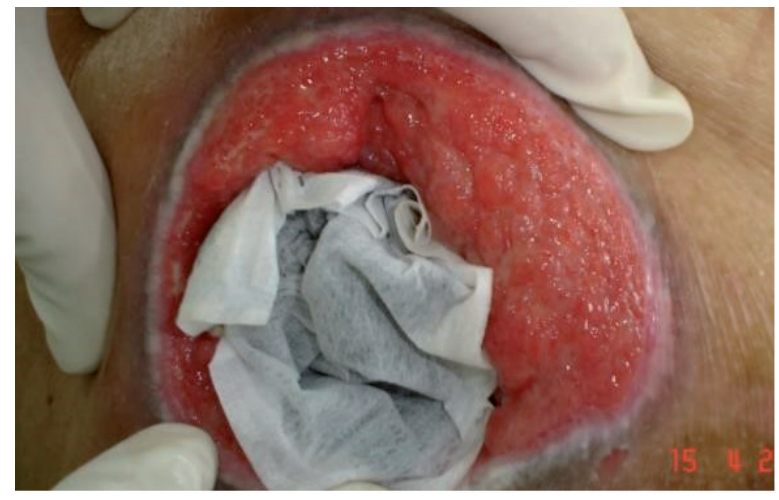

Figura 1. Aplicación del apósito.

Se utilizó un apósito que contiene carbón activado puro impregnado con plata (25 microgramos).

Las heridas se limpiaban por medio de irrigación con solución salina al $0,9 \%$, en cinco casos las heridas presentaban exposición de tendones ( $\mathrm{Fi}^{-}$ gura 2), en estos casos se aplicaba gel amorfo con 
el fin de evitar su desecación. La cobertura total se realizó con gasa estéril en la mayoría de heridas.

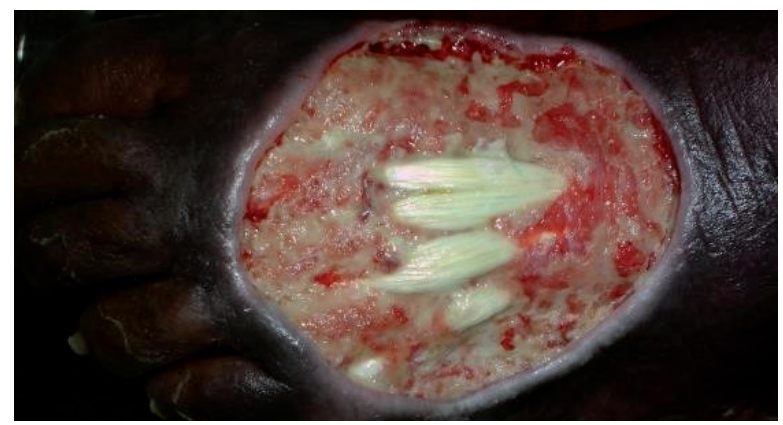

Figura 2. Exposición de tendón.

Algunas heridas presentaban fibrina adherente y costras necróticas adheridas al lecho, después de realizar debridamiento con bisturí, se tomaron muestras para cultivos bacterianos, en donde se informaba recuento de unidades formadores de colonia. (Figura 3).

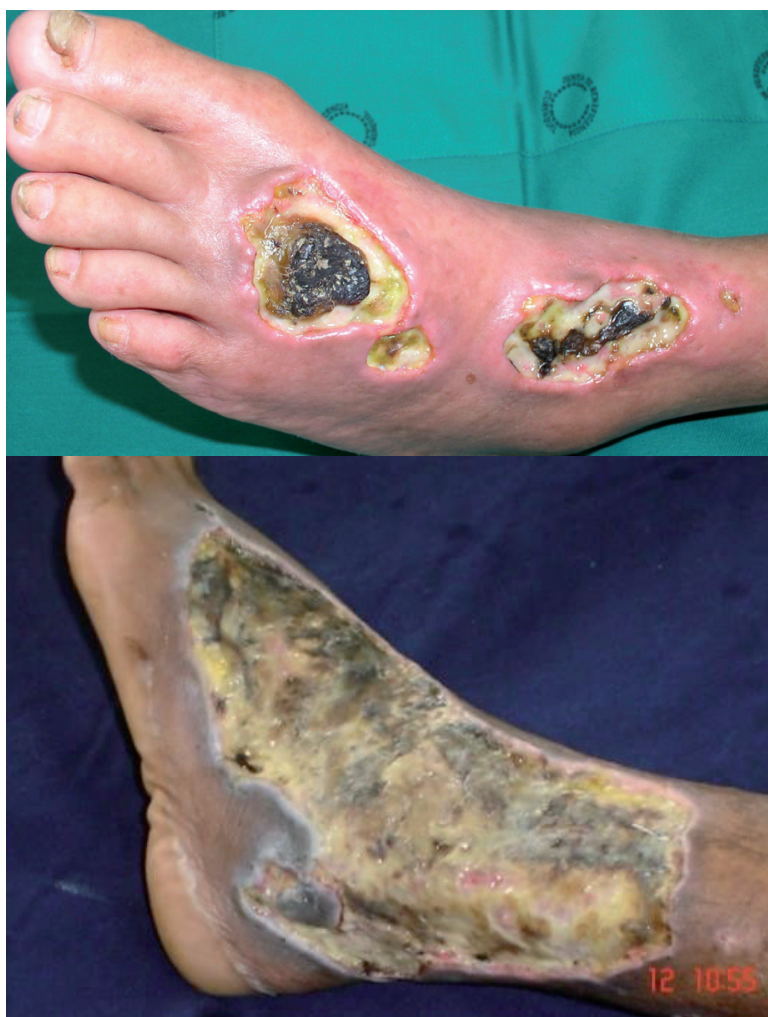

Figura 3. Úlceras de piel con fibrina y costras.

En cada recambio se valoraba: exudado, fondo, bordes, fibrina y tejido de granulación por medio de una escala que va del 0 al 3 en donde los parámetros a estudiar eran: exudado severo, moderado, escaso, y no exudado, fondo limpio o sucio, bordes eritematosos, macerados, pigmentados o del color de la piel y en cuanto al tejido de granulación se valoró si era nulo, escaso, irregular o uniforme, (Tabla 1).
TABLA 1. ESCALA DE EVALUACIÓN DE LAS ÚLCERAS CUTÁNEAS

\section{GRADO CARACTERÍSTICAS}

Exudado severo, fondo sucio, necrosis seca, borde erimatoso, ausencia del tejido de granulación.

1 Exudado moderado, borde macerado o erimatoso, fondo sucio, tejido de granulación escaso.

2 Exudado leve, bordes costrosos, fondo limpio, tejido de granulación de forma irregular.

3 Ausencia de exudado, borde de color salmón, fondo limpio, tejido de granulación uniforme.

Los datos de mayor relevancia de la historia clínica de cada caso se observan en la tabla 2.

\section{TABLA 2. DETALLE DE LOS CASOS}

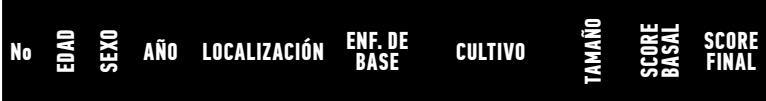

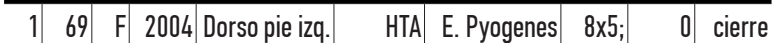

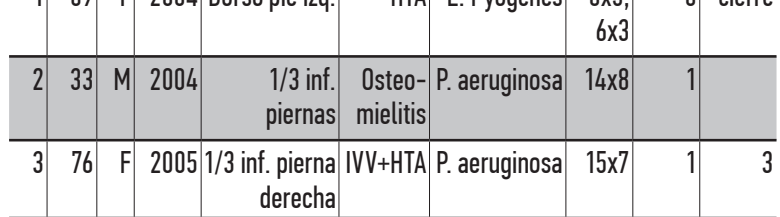
\begin{tabular}{lllllllll}
\hline 4 & 38 & M & 2005 & $1 / 3$ & inf. pierna ninguna P. aeruginosa $20 \times 10$ & 0 & 3
\end{tabular}

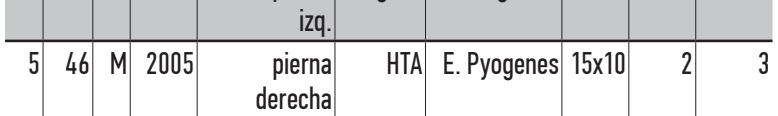

\begin{tabular}{|c|c|c|c|c|c|c|c|c|c|}
\hline 6 & 25 & $\mathrm{~F}$ & 2005 & $\begin{array}{r}1 / 3 \text { inf. pierna } \\
\text { derecha }\end{array}$ & SAF & P. aeruginosa & $6 \times 3$ & 1 & 3 \\
\hline 7 & 68 & M & 2005 & $\begin{array}{r}1 / 3 \text { inf. pierna } \\
\text { derecha }\end{array}$ & VV+HTA & P. Vulgaris & $8 \times 9$ & 1 & 2 \\
\hline 8 & 48 & $\mathrm{~F}$ & 2006 & $\begin{array}{r}1 / 3 \text { inf. pierna } \\
\text { derecha }\end{array}$ & SAF & E. aureus & $6 \times 7$ & 2 & 3 \\
\hline
\end{tabular}

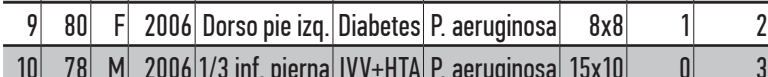

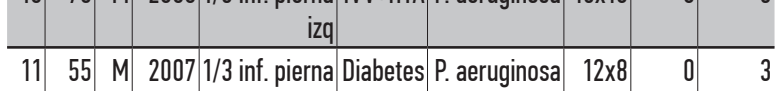

\begin{tabular}{|c|c|c|c|c|c|c|c|c|c|}
\hline & & & 2001 & izq & . & 1. & 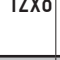 & & \\
\hline 12 & 67 & $\mathrm{~F}$ & 2007 & Dorso pie izq. & Diabetes & P. aeruginosa & $11 \times 7$ & 1 & 3 \\
\hline 13 & 60 & $\mathrm{~F}$ & 2007 & Dorso pie izq & Diabetes & P. aeruginosa & $11 \times 8$ & 1 & 3 \\
\hline 14 & 60 & $F$ & 2008 & $\begin{array}{r}1 / 3 \text { inf. pierna } \\
\text { izq } \\
\end{array}$ & IVV+HTA & P. aeruginosa & $6 \times 5$ & 1 & 3 \\
\hline 15 & 95 & $\mathrm{~F}$ & 2008 & $\begin{array}{r}\text { UPP } \\
\text { Parasacra }\end{array}$ & $\begin{array}{r}\text { Fractura } \\
\text { fémur }\end{array}$ & P. aeruginosa & $12 \times 9$ & 1 & 3 \\
\hline 16 & 17 & $\mathrm{~F}$ & 2008 & Dorso pie izq. & ninguna & A. baumani & $4 \times 3$ & 2 & J \\
\hline
\end{tabular}

En cada recambio se realizaba control fotográfico de las úlceras usando cámara digital de 4,1 megapixeles, utilizando en su gran mayoría como fondo una campo de tela verde. Los datos fueron archivados en programa Microsoft Office Excel (Microsoft Corporation, EEUU).

RESULTADOS

Dieciséis pacientes (10 mujeres y 6 hombres) recibieron tratamiento local con carbón activado más plata durante el período comprendido entre enero de 2004 a julio de 2008. 
En cuanto a la distribución por sexo la mayoría correspondió al femenino; la edad mínima fue de 17 años y la edad máxima fue de 95 años, con una media de 7 años, una mediana de 48 años. En cuanto a la topografía se observó que la mayoría ( 11 casos) se localizó en el tercio inferior de las piernas.

$\mathrm{Al}$ inicio la úlcera de mayor tamaño fue de $20 \mathrm{x}$ $10 \mathrm{cms}$ de diámetro y la de menor tamaño fue de 4 x $3 \mathrm{cms}$. El score grado $\mathrm{l}$ al inicio fue de 0 en cuatro casos, 1 en nueve casos, 2 en tres casos. Al finalizar el tratamiento el score cambió de la siguiente forma: grado 2 en dos casos, y grado 3 en doce casos (Figura 4), un caso presentó cierre completo (Figura 5), no hubo ningún score grado o ni de grado 1 , lo cual evidencia la efectividad del tratamiento local utilizado.

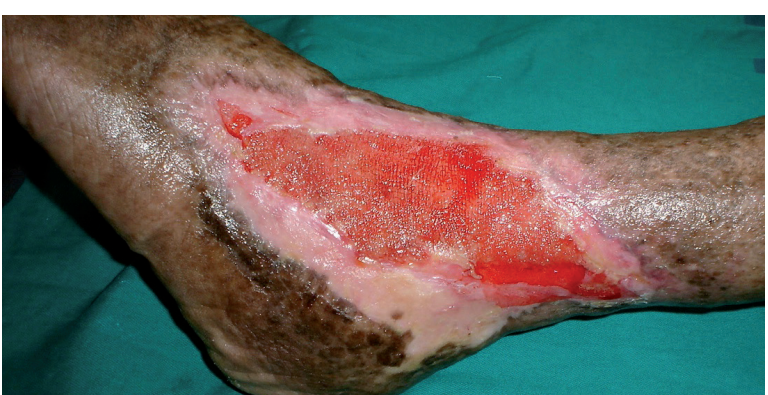

Figuras 4. Úlcera cutánea con score grado 3.

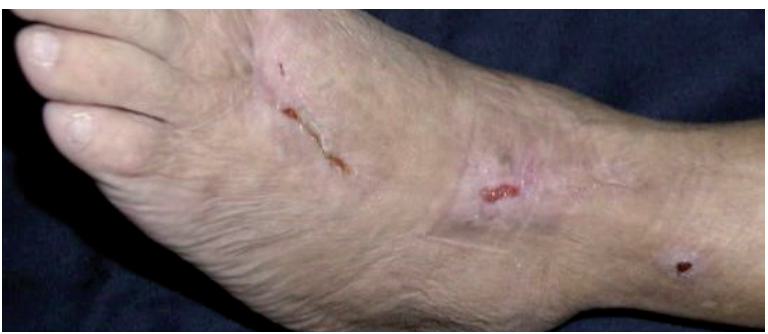

Figuras 5. Epitelización completa.

El cultivo bacteriano reveló presencia de P. aeruginosa en once casos, E. pyogenes en dos casos, E. aureus un caso, Acinetobacer baumanni un caso, y el Proteus vulgaris un caso. Al finalizar el tratamiento no hubo signos clínicos de infección. Ninguna paciente reportó dolor ni al aplicar ni al retirar el apósito, no hubo ningún efecto colateral que se produjera por el uso del carbón activado más plata lo cual nos refleja su buena tolerabilidad y seguridad.

DISCUSIÓN

En la actualidad el manejo local de heridas basado en un ambiente húmedo es el gold estándar en la curación de heridas. Los casos reportados en este artículo sucedieron hace doce años aproximadamente y, hay que reconocer que aun existía des- confianza de parte de pacientes cuyo tratamiento inicial en sus heridas eran: panela, soluciones yodadas, aplicación directa de anfibios entre otros, y siempre se inclinaban a la realización de tres $\mathrm{Cu}^{-}$ raciones diarias. El escepticismo de los pacientes hacia una cura húmeda con apósitos activos fué la dificultad que se afrontó; sin embargo es de resaltar la importancia que un Servicio Médico en este caso de Dermatología sea el sitio de formación de futuros especialistas en Dermatología ya que el diseño curricular incluye clínica de úlceras, lo cual motiva a que esta materia sea investigada. Diversos artículos médicos en relación a heridas manejadas en dicho servicio médico, han sido reportados tanto en revistas como en congresos nacionales e internacionales. Al HLV Servicio Médico de Dermatología son referidos pacientes procedentes de las diversas provincias del país, con heridas de diversas etiologías que van desde infecciosas hasta autoinmunes, en pacientes cuyo compromiso inmunológico en algunas ocasiones está afectado. Con la cura húmeda local que nos aportan los apósitos como el carbón activado más plata, se obtiene: debridamiento y formación de tejido de granulación, de forma rápida, segura y eficiente ya que la institución logra disminuir costos en electricidad, uso de quirófanos, gasas secas, personal de enfermería y médicos; los apósitos son elaborados con el objetivo de ser recambiados en un promedio de 4 a 5 días, en algunos casos hasta en 7 días, el giro de cama se acorta, una vez superado su compromiso sistémico, tienen alta médica y son manejados de forma ambulatoria una vez por semana.

\section{CONCLUSIONES}

La asociación carbón activado más plata, aplicados localmente en heridas infectadas, en este trabajo establece lo siguiente:

Que la plata produce una disminución de la repuesta inflamatoria, ejerce un efecto bactericida en base a un mecanismo de acción múltiple que disminuye la resistencia bacteriana, el carbón activado adsorbe microorganismos, patógenos, y neutraliza el mal olor.

Se utilizó el apósito con plata en heridas infectadas tanto por gérmenes gram negativos como gram positivos lo cual nos ayudó en la cobertura amplia para algunos microorganismos.

La curación de estas heridas permitiría recuperar a un paciente, desde el punto de vista laboral, familiar lo cual mejora su calidad de vida, lo que 
redunda en un costo beneficio farmacológico conveniente; así como también disminuye la permanencia de horas cama de estos pacientes en las instituciones de salud.

Este trabajo permite establecer una alternativa tópica seria, para la curación de heridas infectadas, queen un futuro no muy lejano podría considerarse como un tratamiento tópico de rutina en esta patología frecuente en nuestro país.

\section{REFERENCIAS BIBLIOGRÁFICAS}

1. Winter GD. Scales, JT: Effect o fair drying and dressings on the surface of a wound. Nature 1963; 197.91

2. Vranckx JJ, Slama J, Preuss S, et al: Wet wound healing. Plast Reconstr Surg 2002; 110: 1680.

3. Leaper DJ. Silver dressings: their role in wound management. International Wound Journal. 2006; 3: 4

4. Russell AD, Hugo WB. Antimicrobial activity and action of silver. Prog Med Chem 1994;31:351-71

5. Richards RM. Antimicrobial action of silver nitrate. Microbios 1981; 31: 83-91

6. Coward JE, Carr HS, Rosenkranz HS. Silver sulphadiazine: effect on the growth and ultrastructure of Staphylococci. Chemotherapy 1973; 19: 348-53

7. Klassen HJ. A historical review of the use of silver in the treatment of burns. II. Renewed interest for silver. Burns 2000;131-38
8. Chaby G. Senet P et al. Dressings for acute and chronic wounds. Arch. Dermatol. 2007: 143, 10: 1.297-1.302

9. Landsdown AB, Sampson B, laupattarakasem P, et al. silver aids healing in the sterile skin wound: experimental studies in the laboratory rat. Br J. Dermatol 1997; 137 (5). 728-35

10. Torra JE, Soldevillla J. Rueda J. Actisorb plus 25 en heridas crónicas sin signos de infección local. Sensus Monografías 2003;5; pag 1-8

11. Nemeth AJ, Eaglstein WH, Wound dressings and local treatment. In: Westerhof W. editor. Leg Ulcers; Diagnosis and treatment. Elsevier Science Publishers, Amsterdam, 1993: 325-333.

12. Drosou A. Falabella A. Kirsner r. Antiseptics on wounds. An area of controversy wounds 2003; 15: 149-166

13. Consenso Internacional. Uso Adecuado de los Apósitos de Plata en las heridas. Consenso del grupo de trabajos de expertos. http://www.woundsinternational.com/ media/issues/591/files/content_10498.pdf

14. Lansdown ABG. A pharmacological and toxicological profile of silver as an antimicrobial agent in medical devices. Adv Pharm Sci 2010; 2010:910686. Epub 2010 aug 24.

15. Salamea Molina Pablo. Manejo de heridas complejas con succión continua en el hospital general Luis Vernaza, servicio de cirugía plástica, reconstructiva y estética. Enero 2011-diciembre 2012. Rev. Med. FCM-UCSG, Año XX, Vol.18, №2 (2014). Págs. 71-74. 